\title{
Effect of Methoxy Substitution on Supramolecular Arrangement of Borondifluorides of 2'-Hydroxy Chalcones and their Solid-State NIR Fluorescence
}

\author{
Anthony D'Aléo, Elena Zaborova, Frédéric Fages*
}

\author{
Aix Marseille Univ, CNRS, CINaM UMR 7325, Campus de Luminy, Case 913, 13288 Marseille, France \\ * Corresponding author's e-mail address: frederic.fages@univ-amu.fr
}

RECEIVED: October 30, 2017 * REVISED: February 9, 2018 * ACCEPTED: February 9, 2018

THIS PAPER IS DEDICATED TO PROF. MLADEN ŽINIĆ ON THE OCCASION OF HIS 70

\begin{abstract}
This work describes the borondifluoride complexes of 2'-hydroxychalcone derivatives, 2 and 3 , differently substituted with methoxy groups. Their optical study in dichloromethane reveals similar UV-vis absorption and fluorescence emission features in the visible spectral region that are close to those of the parent compound 1 . While fluorescence quantum yields $\Phi_{\mathrm{f}}$ are very low in solution, they are higher in the solid state, showing that aggregation-induced enhanced emission occurs. Remarkably, the solid-state emission spectra are strongly red-shifted reaching the near infrared (NIR) spectral range. Molecular structures of $\mathbf{2}$ and $\mathbf{3}$ were determined by single crystal X-ray diffraction. The data show the occurrence of tightly packed arrangements that favor strong $\pi-\pi$ overlap between neighboring molecules. Such situation allows the generation of promising NIR emitting materials, such as compound 3 emitting at $784 \mathrm{~nm}$ with $\Phi_{\mathrm{f}}=0.07$ that stands as one of the best NIR solidstate organic emitters.
\end{abstract}

Keywords: fluorescence, solid state, near infrared, boron complexes, chalcones.

\section{INTRODUCTION}

$\mathbf{T}$ HE three-dimensional supramolecular arrangement of chromophores determines to a great extent the optical properties of their solid-state assemblies. Because applications of those materials is of prime importance in the context of advanced technologies such as sensing, displays and photonics, there is a strong need to establish reliable relationships between the modes of molecular aggregation and fluorescence emission properties. However, despite many efforts, this task remains extremely difficult due to the many parameters pertaining to optical phenomena in the solid-state.

In that context, we reported recently on borondifluoride $\left(\mathrm{BF}_{2}\right)$ complexes of 2'-hydroxychalcones that represent a versatile class of electron donor (D) - acceptor (A) fluorophores. ${ }^{[1-3]}$ Those push-pull systems, in which the $\mathrm{BF}_{2}$-containing cycle acts as $\mathrm{A}$ unit, were shown to display emission in the visible part of the spectrum with useful fluorescence emission quantum yields $\left(\Phi_{f}\right)$ in solution ${ }^{[4-8]}$ and intense near infrared (NIR) emission in the solid state. ${ }^{[1-3]}$ It is generally admitted that intermolecular interactions in the condensed phase of small organic molecules lead to effective fluorescence quenching. Substitution of $\pi$-conjugated systems with bulky side groups that hinder $\pi-\pi$ cofacial stacking prevents aggregation-induced quenching, especially in the case of $\mathrm{H}$-aggregation. Recently, restriction of intramolecular rotation and conformational planarization mechanisms was proposed as a chemical design strategy toward the generation of highly luminescent organic solids in which aggregation-induced emission $(\mathrm{AIE})^{[9,10]}$ or aggregation-induced enhanced emission (AIEE) ${ }^{[11]}$ phenomena operate. In the case of $\mathrm{BF}_{2}$ complexes of 2'-hydroxychalcones and curcuminoids, we showed that NIR emission property is characteristic of tightly packed chromophores experiencing strong excitonic coupling. ${ }^{[3,12]} \mathrm{A}$ similar behavior has been reported to account for "excited multimer" fluorescence in stacks of diaroylmethanoboron difluoride molecules built on $\pi$-orbital overlap between benzene and dioxaborine rings. ${ }^{[13]}$ Therefore, the solid-state optical

(c) $\mathbf{B Y}$ This work is licensed under a Creative Commons Attribution 4.0 International License. 
<smiles></smiles><smiles></smiles><smiles></smiles><smiles></smiles>

Scheme 1. Molecular structures of compounds 1-4.

signature of difluoroboron $\beta$-diketonate dyes is generally strongly sensitive to supramolecular packing. Especially, in the case of analogous dyes based on chalcone ligands, aggregation underpins the considerable spectral shift toward long wavelengths and an aggregation induced NIR emission (AI-NIR-E) phenomenon thus operates.

In this work, we report the effect of methoxy group substitution at ring $\mathrm{A}$ (Scheme 1 ) in $\mathrm{BF}_{2}$ complexes of three homologous 2'-hydroxychalcone derivatives, 1-3. Compounds containing a para-methoxy group, namely the closely related dye 1 and compound $\mathbf{4}$ that features an acetonaphthone instead of the acetophenone unit in part $B$, have already been published and are used here for the sake of comparison. The two new molecules, $\mathbf{2}$ and $\mathbf{3}$, bear one ortho-methoxy and two ortho,para-methoxy groups, respectively. Using UV-vis absorption and fluorescence spectroscopy and single-crystal X-ray analysis, we show that those compounds adopt very different packing arrangements leading to specific optical characteristics. Especially, dye $\mathbf{3}$ exhibits a considerably red-shifted emission in the solid state, with a maximum at $784 \mathrm{~nm}$ and a $\Phi_{\mathrm{f}}$ value of 0.07 , which represents an example of very efficient NIR-emitting organic dye.

\section{EXPERIMENTAL}

\section{Synthesis}

All solvents for synthesis were of analytic grade. NMR spectra $\left({ }^{1} \mathrm{H},{ }^{13} \mathrm{C},{ }^{19} \mathrm{~F}\right)$ were recorded at room temperature on a BRUKER AC 250 operating at 250 and $235 \mathrm{MHz}$ for ${ }^{1} \mathrm{H}$ and ${ }^{19} \mathrm{~F}$, respectively. Data are listed in parts per million (ppm) and are reported relative to tetramethylsilane $\left({ }^{1} \mathrm{H}\right.$ and ${ }^{13} \mathrm{C}$ ); residual solvent peaks of the deuterated solvents were used as an internal standard. Mass spectra and elemental analyses were realized in Spectropole de Marseille (http://www.spectropole.fr/). Compound $\mathbf{1}$ was synthesized according to a published procedure. The synthesis of the free ligands precursor of dyes $\mathbf{2}^{[14]}$ and $\mathbf{3}^{[15]}$ was reported in literature.

\section{Procedure for the Preparation of the BF2 Complexes}

In a $50 \mathrm{~mL}$ round bottom flask, the 2'-hydroxychalcone derivative (1 mol eq) was solubilized in dichloromethane. Boron trifluoride etherate $(1.3 \mathrm{~mol}$ eq) was added and the solution was refluxed for 3 hours. The solution was concentrated, cooled down and the precipitate was filtered off, cleaned with ether and air dried yielding the pure product.

2. ${ }^{1} \mathrm{H}-\mathrm{NMR}\left(250 \mathrm{MHz}, \mathrm{CDCl}_{3}\right): 8.76\left(\mathrm{~d},{ }^{3} \mathrm{~J}=15.3 \mathrm{~Hz}\right.$, $1 \mathrm{H}), 7.92\left(\mathrm{dd},{ }^{3} \mathrm{~J}=8.3 \mathrm{~Hz},{ }^{4} J=1.5 \mathrm{~Hz}, 1 \mathrm{H}\right), 7.83\left(\mathrm{~d},{ }^{3} J=15.3 \mathrm{~Hz}\right.$, $1 \mathrm{H}), 7.70(\mathrm{~m}, 2 \mathrm{H}), 7.54(\mathrm{~d}, 3 \mathrm{~J}=8.8 \mathrm{~Hz}, 4 \mathrm{~J}=1.6 \mathrm{~Hz}, 1 \mathrm{H}), 7.15$ $(\mathrm{d}, 3 \mathrm{~J}=8.3 \mathrm{~Hz}, 1 \mathrm{H}), 7.08(\mathrm{~d}, 3 \mathrm{~J}=7.8 \mathrm{~Hz}, 1 \mathrm{H}), 7.02(\mathrm{~m}, 2 \mathrm{H})$, 4.01 (s, 3H); ${ }^{19} \mathrm{~F}-\mathrm{NMR}\left(235 \mathrm{MHz}, \mathrm{CDCl}_{3}\right)$ : $-141.95\left({ }^{10} \mathrm{~B}-\mathrm{F}\right.$, $0.4 \mathrm{~F}),-124$. (11B-F, 1.6F). HR-MS $\left(\mathrm{ESI}^{+}\right)$calcd for $\mathrm{C}_{16} \mathrm{H}_{13} \mathrm{O}_{3} \mathrm{BF}_{2} \mathrm{Na}^{+} \mathrm{m} / \mathrm{z}=325.0824[\mathrm{M}+\mathrm{Na}]^{+}$; found 325.0819 $[\mathrm{M}+\mathrm{Na}]^{+}$.

3. ${ }^{1} \mathrm{H}-\mathrm{NMR}\left(250 \mathrm{MHz}, \mathrm{CDCl}_{3}\right): 8.71\left(\mathrm{~d},{ }^{3} \mathrm{~J}=15.0 \mathrm{~Hz}\right.$, $1 \mathrm{H}), 7.89\left(\mathrm{dd}, 3 \mathrm{~J}=8.4 \mathrm{~Hz},{ }^{4} J=1.6 \mathrm{~Hz}, 1 \mathrm{H}\right), 7.67(\mathrm{~m}, 3 \mathrm{H}), 7.13$ $\left(\mathrm{dd},{ }^{3} \mathrm{~J}=8.5 \mathrm{~Hz},{ }^{4} \mathrm{~J}=1.0 \mathrm{~Hz}, 1 \mathrm{H}\right), 7.00\left(\mathrm{dt},{ }^{3} \mathrm{~J}=8.3 \mathrm{~Hz},{ }^{4} \mathrm{~J}=\right.$ $1.0 \mathrm{~Hz}, 1 \mathrm{H}), 6.62\left(\mathrm{dd},{ }^{3} J=8.7 \mathrm{~Hz},{ }^{4} J=2.2 \mathrm{~Hz}, 1 \mathrm{H}\right), 6.49\left(\mathrm{~d},{ }^{4}\right.$ $J=2.2 \mathrm{~Hz}, 1 \mathrm{H}), 4.00(\mathrm{~s}, 3 \mathrm{H}), 3.92(\mathrm{~s}, 3 \mathrm{H}) ;{ }^{19} \mathrm{~F}-\mathrm{NMR}(235 \mathrm{MHz}$, $\left.\mathrm{CDCl}_{3}\right)$ : $-142.76\left({ }^{10} \mathrm{~B}-\mathrm{F}, 0.4 \mathrm{~F}\right),-142.83\left({ }^{11} \mathrm{~B}-\mathrm{F}, 1.6 \mathrm{~F}\right)$. HR-MS $\left(\mathrm{ESI}^{+}\right.$) calcd for $\mathrm{C}_{17} \mathrm{H}_{15} \mathrm{O}_{4} \mathrm{BF}_{2} \mathrm{Na}^{+} \mathrm{m} / \mathrm{z}=355.0929[\mathrm{M}+\mathrm{Na}]^{+}$; found $355.0932[\mathrm{M}+\mathrm{Na}]^{+}$.

\section{Spectroscopy and X-ray Structure Determination}

Spectroscopy measurements were carried out with spectroscopic grade solvents. UV / Vis-absorption spectra were measured on a Varian Cary 50. Solid-state spectra were measured by dropcasting a solution of the compound in dry $\mathrm{CH}_{2} \mathrm{Cl}_{2}$ onto a quartz plate and correcting for a scatteredlight background. Emission spectra were measured on a Horiba-JobinYvon Fluorolog-3 spectrofluorimeter. Solution-phase fluorescence quantum yields were determined according to classical procedure. Solid-state spectra and luminescence quantum yields of powder samples were recorded using an integrating sphere.

X-ray structure determination was performed according to previously published methodologies.

\section{RESULTS AND DISCUSSION}

\section{Synthesis}

The two 2'-hydroxychalcone derivatives $\mathbf{2}$ and $\mathbf{3}$ were prepared by using a Claisen-Schmidt coupling reaction between acetophenone and 2-methoxybenzaldehyde or 2,4-dimethoxybenzaldehyde, respectively, yielding the corresponding free ligands. The reactions were performed in refluxing ethanol solution ( $16 \mathrm{~h}$ ) using sodium hydroxide as a base. Boron difluoride complexes were obtained quantitatively by reacting the ligands with a slight excess of boron 
Table 1. . UV-vis absorption and fluorescence emission data for compounds 1-3 in solution (DCM) and in the solid state.

\begin{tabular}{|c|c|c|c|c|c|c|c|}
\hline \multirow{3}{*}{ Compound } & \multicolumn{4}{|c|}{ Solution } & \multicolumn{3}{|c|}{ Solid state } \\
\hline & \multicolumn{2}{|c|}{ Abs } & \multicolumn{2}{|c|}{ Fluo $^{(a),(b)}$} & \multirow{2}{*}{$\frac{\mathrm{Abs}^{(\mathrm{c})}}{\lambda_{\mathrm{abs}} / \mathrm{nm}}$} & \multicolumn{2}{|c|}{ Fluo $^{(b),(d)}$} \\
\hline & $\lambda_{\text {abs }} / \mathrm{nm}$ & $\varepsilon / \mathrm{M}^{-1} \mathrm{~cm}^{-1}$ & $\lambda_{\mathrm{em}} / \mathrm{nm}$ & $\Phi_{\mathrm{f}}$ & & $\lambda_{\mathrm{em}} / \mathrm{nm}$ & $\Phi_{\mathrm{f}}$ \\
\hline 1 & 455 & 41190 & 556 & 0.02 & 350 & 627 & 0.21 \\
\hline 2 & 449 & 35120 & 576 & 0.01 & 472 & 698 & 0.07 \\
\hline 3 & 479 & 39970 & 532 & 0.03 & 414 & 784 & 0.07 \\
\hline
\end{tabular}

\footnotetext{
(a) Diluted solutions (ca. $\left.10^{-6} \mathrm{M}\right)$.

(b) Excitation at maximum absorption wavelength.

(c) Drop casted films.

(d) Powder.
}

trifluoride etherate in dichloromethane (DCM). While all boron difluoride complexes of 2'-hydroxychalcones investigated here were found to be highly stable in the solid state and in solvents free of protic species. For example, hydrolytic clevage of the $\mathrm{B}-\mathrm{O}$ bond induced the release of the $\mathrm{BF}_{2}$ group in DCM containing $0.5 v / v \%$ with kinetic constants in the range of $10^{-3}$ to $10^{-2} \mathrm{~min}^{-1}$.

\section{UV-vis and Fluorescence Emission Properties in Solution}

Optical properties of 1-3 were investigated in dichloromethane (DCM) solution. The data are collected in Table 1.

Like the case of $1,^{[1]}$ the electronic absorption spectra of $\mathbf{2}$ and $\mathbf{3}$ in DCM (Figure 1) display an intense lowest-energy transition band located between 450 and $480 \mathrm{~nm}$. The maximum absorption of 3 is at a longer wavelength compared to $\mathbf{1}$, which may be due to the presence of two electron donor groups on the $A$ ring. Compound $\mathbf{2}$ has the more blue-shifted absorption spectrum relative to $\mathbf{1}$ and $\mathbf{3}$. This sequence is found consistent with that noticed for $\mathrm{BF}_{2}$ complexes of curcuminoids bearing the same series of terminal aryl groups. ${ }^{[16]}$ However, steady-state fluorescence spectroscopy shows a peculiar behavior for $\mathbf{2}$ and even more for $\mathbf{3}$. Compound $\mathbf{2}$ emits at the longest wavelength $(576 \mathrm{~nm})$ while the spectrum of $\mathbf{3}$ is considerably blue-shifted relative to that of 1. Using solvents of increasing polarity, we observed that the UV-vis absorption and fluorescence spectra of $\mathbf{1}$ and $\mathbf{2}$ are red-shifted (Figure S1), which shows that the electronic transitions have an intramolecular charge transfer character as observed for this family of D-A molecules. In the case of $\mathbf{2}$, the Stokes shift value remains somewhat constant (ca. $5000 \mathrm{~cm}^{-1}$ ) from apolar to polar solvents. Strikingly, while the absorption spectrum of $\mathbf{3}$ also shows a positive solvatochromic shift, its fluorescence emission spectrum is blue-shifted when solvent polarity increases. As a result, the Stokes shift decreases in polar relative to apolar solvents (Figure S2). Such a behavior is quite unusual and still remains unclear. One possible explanation would be that relaxation from the Franck-Condon to the emitting state reduces the excited-state dipole moment leading, in turn, to less stabilization of the relaxed emitting state in polar solvents. For the three compounds investigated, we obtained weak values of $\Phi_{\mathrm{f}}$ in DCM $(<2 \%)$ which shows that non radiative deactivation pathways, such as intramolecular rotation processes, are very efficient within those dyes. ${ }^{[1]}$

\section{X-ray Structure Analysis}

The single-crystal structure of compound $\mathbf{1}$ has been reported elsewhere. ${ }^{[1]}$ Slow evaporation of solution of $\mathbf{2}$ and $\mathbf{3}$ in dry dichloromethane solution containing ethyl

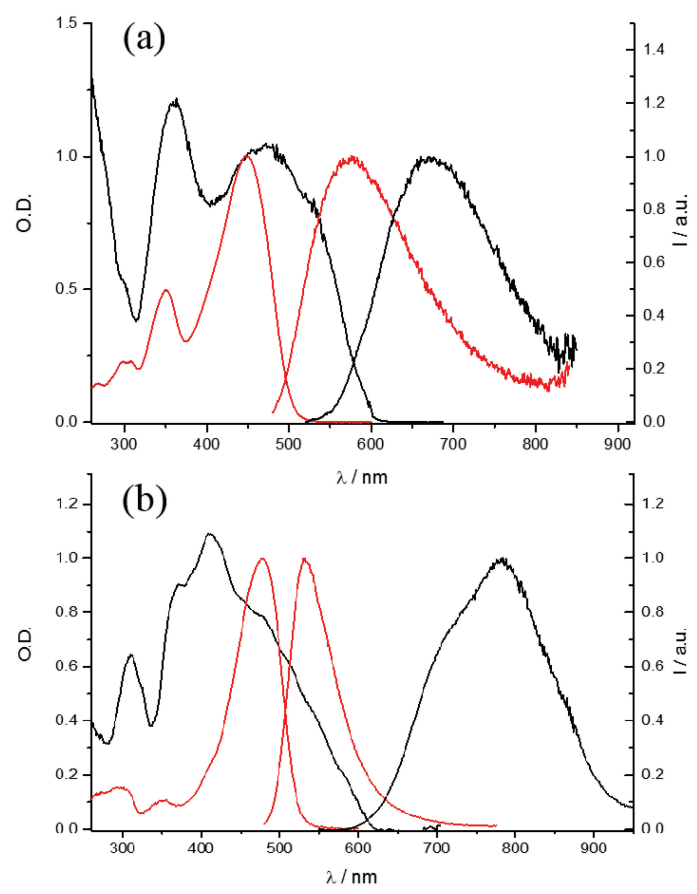

Figure 1. UV-vis absorption and fluorescence emission spectra of compounds $\mathbf{2}$ (a) and $\mathbf{3}$ (b) in solution (DCM, red lines) and in the solid state (thin film, black lines). 
acetate afforded single crystals suitable for X-ray structure analysis. Both compounds $\mathbf{1}$ and $\mathbf{2}$ are found to crystallize in the monoclinic system with the $\mathrm{P} 2_{1} / \mathrm{c}$ space group while 3 adopts the triclinic system with the P-1 space group (Table 2).

The three dyes display a coplanar $\pi$-conjugated backbone (Figure S3). The new molecule 3 shows packing features that are similar to that of $\mathbf{1}$. Indeed the $\pi$-conjugated systems experience an antiparallel face-to-face superimposition with a large contact area so that the $D(A)$ unit of one molecule faces the $A(D)$ unit of the neighboring molecule (Figure 2). Moreover, the $\mathrm{BF}_{2}$ rings of two pairwise associated molecules exhibit a head-to-tail orientation. All together, these features tend to provide a strong driving force for crystal packing inasmuch as they favor electrostatic D-A and dipole-dipole interactions. The

Table 2. Selected crystal data for compounds $\mathbf{2}$ and $\mathbf{3}$.

\begin{tabular}{|c|c|c|}
\hline & 2 & 3 \\
\hline Formula & $\mathrm{C}_{16} \mathrm{H}_{13} \mathrm{BF}_{2} \mathrm{O}_{3}$ & $\mathrm{C}_{17} \mathrm{H}_{15} \mathrm{BF}_{2} \mathrm{O}_{4}$ \\
\hline$M / g$ & 302.07 & 332.1 \\
\hline Size $/ \mathrm{mm}^{3}$ & $0.25 \times 0.16 \times 0.02$ & $0.2 \times 0.18 \times 0.03$ \\
\hline Crystal System & Monoclinic & Triclinic \\
\hline Space group & $\mathrm{P} 2{ }_{1} / \mathrm{C}$ & $\mathrm{P}-1$ \\
\hline$a / \AA$ & $7.5538(2)$ & $7.3620(4)$ \\
\hline$b / \AA$ & $17.6192(7)$ & $8.2643(4)$ \\
\hline$c / \AA$ & $11.2042(4)$ & $13.475(1)$ \\
\hline$\alpha / \operatorname{deg}$ & 90 & $100.193(2)$ \\
\hline$\beta / \operatorname{deg}$ & 106.121(3) & $96.916(3)$ \\
\hline$\gamma /$ deg & 90 & $109.282(6)$ \\
\hline$V / \AA^{3}$ & $1432.55(9)$ & $747.39(8)$ \\
\hline Z & 4 & 2 \\
\hline$\lambda(\mathrm{Mo} / \mathrm{K} \alpha) / \AA$ & 0.71073 & 0.71073 \\
\hline$T / K$ & $293(2)$ & $293(2)$ \\
\hline$D c / \mathrm{g} \mathrm{cm}^{-3}$ & 1.401 & 1.476 \\
\hline$\theta$ range / deg & $3.64-28.52$ & $1.56-26.37$ \\
\hline$h k l$ ranges & $\begin{array}{c}0<h<10 \\
0<k<23 \\
-14<l<13\end{array}$ & $\begin{array}{c}0<h<9 \\
-10<k<9 \\
-16<l<16\end{array}$ \\
\hline Refln measured & 16034 & 9016 \\
\hline Refln $I>2 \sigma(I)$ & 3479 & 3060 \\
\hline $\mathrm{R} 1 />2 \sigma(\mathrm{I})$ & 0.0675 & 0.0796 \\
\hline R1 all data & 0.1364 & 0.1505 \\
\hline$w R 2 I>2 \sigma(I)$ & 0.145 & 0.2159 \\
\hline$w R 2$ all data & 0.1881 & 0.2833 \\
\hline$\Delta \rho(+/-) /$ e $\AA^{-3}$ & $\begin{array}{c}\min -0.203 \\
\max 0.178\end{array}$ & $\begin{array}{c}\min -0.604 \\
\max 0.523\end{array}$ \\
\hline
\end{tabular}

shortest interplanar distance in $\mathbf{3}$ (3.39 $\AA$ ) is similar to that in $\mathbf{1}(3.38 \AA ̊ \AA)$, which corresponds to a significant intermolecular overlap of $\pi$-orbitals. Furthermore, compounds 1 and 3 form discrete 1-D stacks oriented along the $a$ axis. But unlike 1, molecules of $\mathbf{3}$ form parallel chains that are perfectly aligned along the $c$ axis and contained in planes parallel to the (100) plane (Figure 2). As such, the structure is reminiscent of the previously published analogous compound 4.

Dye $\mathbf{2}$ adopts a different packing arrangement in the crystal (Figure 3). Although the molecules experience the same kind of pairwise association with the occurrence of head-to-tail cofacial dimers maintained at the interplanar van der Waals distance (3.42 $\AA$ ), one does not observe the formation of extended stacks of those dimers. Instead, the connection between two neighboring dimers occurs through lateral $\pi-\pi$ interaction between ortho-anisole rings of adjacent molecules (inter ring distance $3.597 \AA ̊$ ). As a result, the single-crystal structure shows a kind of herringbone arrangement (Figure 3a). This lateral interaction involves the antiparallel orientation of the local dipole moments borne by the $\mathrm{C}-\mathrm{O}$ bond of the associated anisole units and leads to staggered assemblies of two molecules of 2 (Figure 3b).

\section{Solid-State Optical Properties}

The solid-state UV-vis absorption spectra of thin films that were drop-cast from solutions in $\mathrm{CH}_{2} \mathrm{Cl}_{2}$ were recorded in the transmission mode (Figure 1, Table 1). The absorption

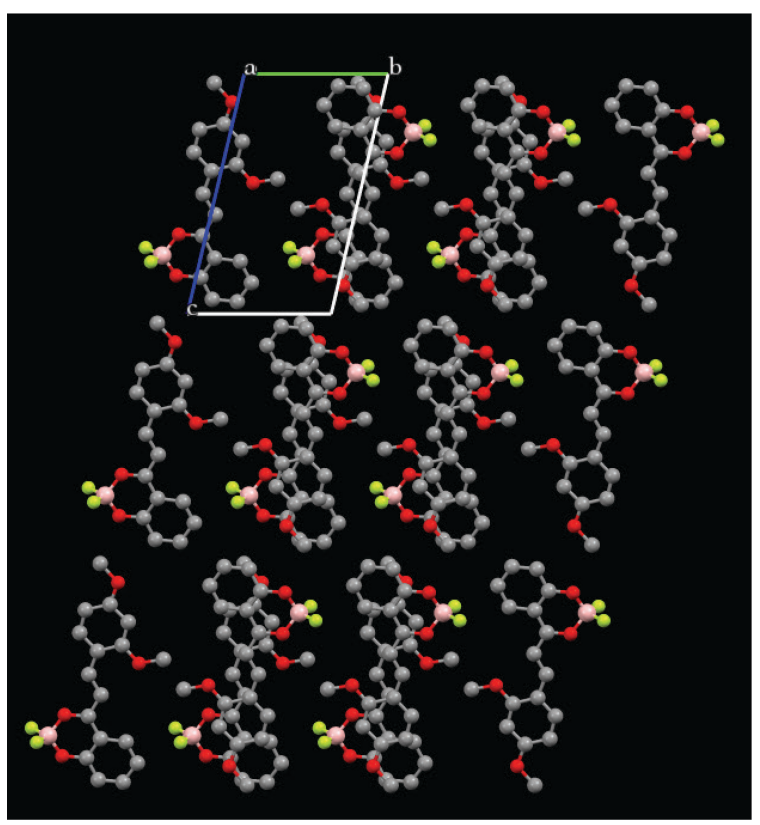

Figure 2. View of $\pi$-stacks along $a$ axis and parallel chains contained in planes parallel to the (100) plane formed by 3 in the crystal. Hydrogen atoms were omitted for clarity. 
spectrum of compound $\mathbf{1}$ was found hypsochromically shifted relative to the solution, which correlated with $\mathrm{H}$-like aggregate formation in the solid state. Like compound 4, 3 displayed a complex absorption spectrum that was interpreted in term of the occurrence of $\pi$-stacks and dipole chains. Such combination of molecular arrangements provides the basis for a more complex Davydov splitting ${ }^{[18]}$ compared to 1 . The absorption maximum, however, was found at high energy relative to the solution. In the case of 2, the lowest-energy absorption band is found at smaller energy of in the solid state than that in DCM solution. This optical signature is consistent with the aforementioned packing of dye $\mathbf{2}$ that features the typical J-type arrangement of the chromophoric units.

The two new compounds $\mathbf{2}$ and $\mathbf{3}$ were found to be emissive in the solid state (Table 1, Figure 1). The spectra are characterized by broad emission bands with maxima that are considerably red-shifted as compared to DCM solution (122 nm for $\mathbf{2}$ and up to $252 \mathrm{~nm}$ for $\mathbf{3}$ ). A very large
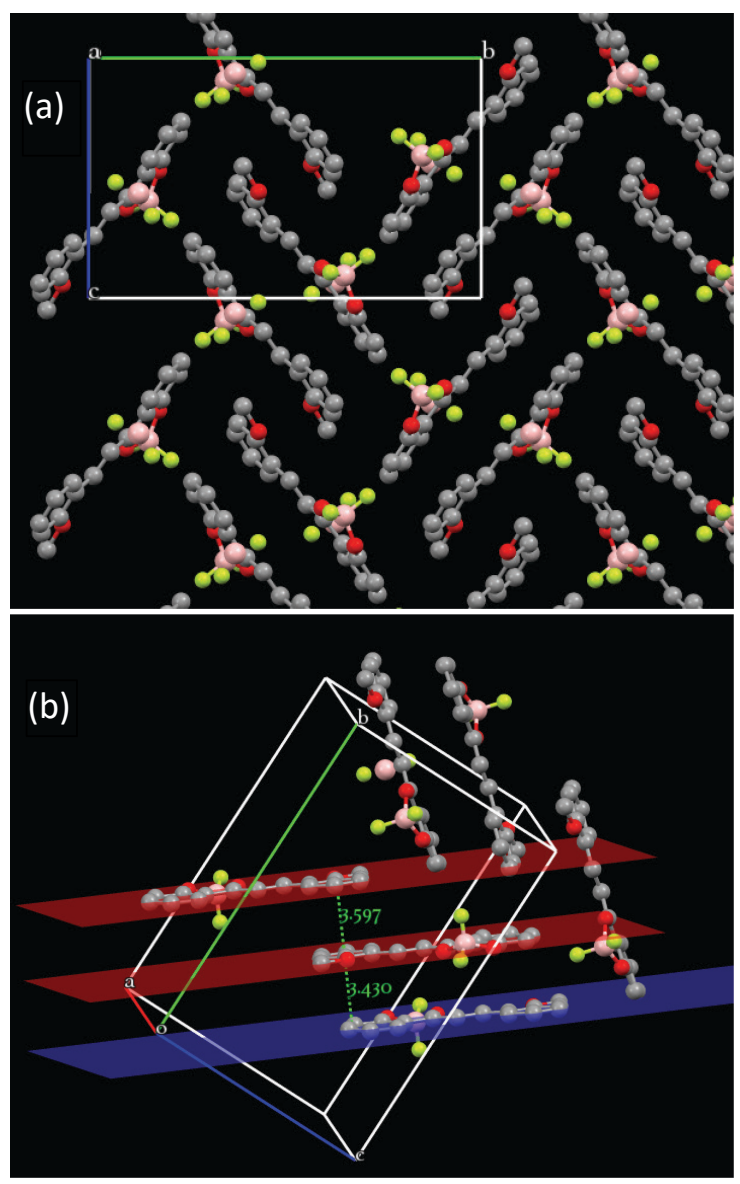

Figure 3. Views of of the crystal structure of dye 3 (a) along $a$ axis and and (b) showing details of the two types of pairwise association. Hydrogen atoms were omitted for clarity. value of the Stokes shift $\left(>10000 \mathrm{~cm}^{-1}\right)$ is measured for $\mathbf{3}$ while the value is smaller for $\mathbf{2}\left(6860 \mathrm{~cm}^{-1}\right)$. The solid-state $\Phi_{\mathrm{f}}$ values obtained for $\mathbf{2}$ and $\mathbf{3}$ are lower than those determined for 1 . However, they are much higher (ca. $7 \%$ ) than the values found in DCM solution. This observation indicates that AIEE operates in the condensed phase, possibly in combination with chromophore planarization effect on the radiative deactivation of the excited state. As observed previously, tight aggregation enables considerably redshifted emission spectra for $\mathbf{2}$ and $\mathbf{3}$ along with significant values of the solid-state fluorescence quantum yield, showing that AI-NIR-E is also operative.

\section{CONCLUSION}

This study shows that the two borondifluoride complexes $\mathbf{2}$ and $\mathbf{3}$ display interesting solid-state fluorescence properties owing to the AIEE effect. Especially, it can be seen that such structurally simple molecules obtained from expeditious synthetic routes display outstanding NIR emission features in thin films that could find applications in advanced technologies for (opto)electronics. This study also shows that NIR emission stems from the tight packing of dye molecules, which allows them to experience extended intermolecular $\pi-\pi$ overlap. Under such conditions of crystal arrangement, it is quite amazing that solid-state fluorescence quantum yields are larger relative to those determined in solution. As such, this effect strongly suggests the occurrence of an aggregation induced NIR emission process. Our results confirm that such effect is sensitive to subtle changes in the chemical structure of the dyes, as it is the case for $\mathbf{2}$ and $\mathbf{3}$ featuring closely-related substitution patterns.

Acknowledgment. We acknowledge the financial support from Aix Marseille University and the Centre National de la Recherche Scientifique (CNRS). We thank Dr. Michel Giorgi (Spectropole, Marseille) for single-crystal XRD measurements.

Supplementary Information. Supporting information to the paper is attached to the electronic version of the article at: http://doi.org/10.5562/cca3241.

\section{REFERENCES}

[1] A. D’Aléo, D. Gachet, V. Heresanu, M. Giorgi, F. Fages, Chem. Eur. J. 2012, 18, 12764.

[2] S. Chambon, A. D'Aléo, C. Baffert, G. Wantz, F. Fages, Chem. Commun. 2013, 49, 3555.

[3] A. D'Aléo, V. Heresanu, M. Giorgi, B. Le Guennic, D. Jacquemin, F. Fages, J. Phys. Chem. C 2014, 118, 11906.

[4] H. Reyes, M. Conception Garcia, B. M. Flores, H. Lopez-Rebolledo, R. Santillan, N. Farfan, J. Mex. Chem. Soc. 2006, 50, 106. 
[5] J. A. VanAllan, G. A. Reynolds, J. Heterocycl. Chem. 1969, 6, 29.

[6] A. R. Alcantara, J. M. Marinas, J. V. Sinisterra, Tetrahedron Lett. 1987, 28, 1515.

[7] M. G. Marathey, J. Org. Chem. 1955, 20, 563.

[8] K. B. Raut, S. H. Wender, J. Org. Chem. 1960, 25, 50.

[9] Y. Hong, J. W. Y. Lama, B. Z. Tang, Chem. Commun. 2009, 4332.

[10] Y. Hong, J. W. Y. Lama, B. Z. Tang, Chem. Soc. Rev. 2011, 40, 5361.

[11] B.-K. An, J. Gierschner, S. Y. Park, Acc. Chem. Res. 2012, 45, 544.

[12] A. D'Aléo, A. Felouat, V. Heresanu, A. Ranguis, D. Chaudanson, A. Karapetyan A, M. Giorgi, F. Fages, J. Mater. Chem. C 2014, 2, 5208.
[13] A. Sakai, E. Ohta, Y. Yoshimoto, M. Tanaka, Y. Matsui, K. Mizuno, H. Ikeda, Chem. Eur. J. 2015, 21, 18128.

[14] A. Detsi, M. Majdalani, C. A. Kontogiorgis, D. Hadjipavlou-Litina, P. Kefalas, Bioorg. Med. Chem. 2009, 17, 8073.

[15] F. Manna, F. Chimenti, A. Bolasco, M. L. Cenicola, M. D'Amico, C. Parrillo, F. Rossi, E. Marmo, Eur. J. Med. Chem. 1992, 27, 633.

[16] A. Felouat, A. D'Aléo, F. Fages, J. Org. Chem. 2013, 78, 4446.

[17] Canard G, Ponce-Vargas M, Jacquemin D, Le Guennic B, Felouat A, Rivoal M, E. Zaborova, A. D'Aléo, F. Fages, RSC Adv. 2017, 7, 10132.

[18] M. Kasha, H. R. Rawls, M. Ashrad El-Bayoumi, Pure Appl. Chem. 1965, 11, 371. 